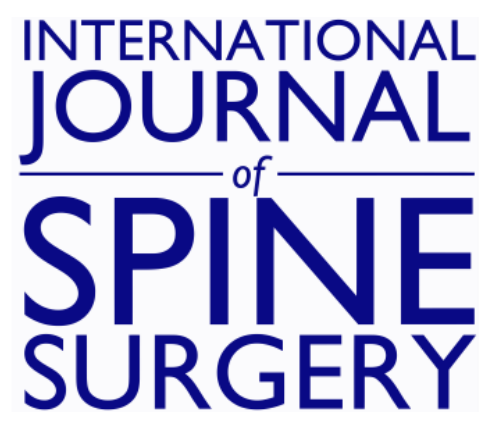

\title{
Determination of Work Relative Value Units for Management of Lumbar Spinal Stenosis by Open Decompression and Interlaminar Stabilization
}

Delaine Lorio, Matthew Twetten, S. Raymond Golish and Morgan P. Lorio

Int J Spine Surg 2021, 15 (1) 1-11

doi: https://doi.org/10.14444/8026

http://ijssurgery.com/content/15/1/1

This information is current as of April 26, 2023.

Email Alerts Receive free email-alerts when new articles cite this article. Sign up at:

http://ijssurgery.com/alerts

The International Journal of Spine Surgery

2397 Waterbury Circle, Suite 1,

Aurora, IL 60504, Phone: +1-630-375-1432 


\title{
Determination of Work Relative Value Units for Management of Lumbar Spinal Stenosis by Open Decompression and Interlaminar Stabilization
}

\author{
DELAINE LORIO, MA (SCOTLAND), ${ }^{1}$ MATTHEW TWETTEN, MA, MBA, ${ }^{2}$ S. RAYMOND GOLISH, MD, \\ PHD, MBA, ${ }^{3}$ MORGAN P. LORIO, MD, FACS ${ }^{4}$ \\ ${ }^{I}$ University of Edinburgh Business School, Edinburgh, Scotland, ${ }^{2}$ International Society for the Advancement of Spine Surgery, Wheaton, Illinois, ${ }^{3} J F K$ Hospital, \\ HCA Healthcare, Palm Beach, Florida, ${ }^{4}$ Advanced Orthopedics, Altamonte Springs, Florida
}

\begin{abstract}
Background: Effective January 1, 2017, open surgical decompression and interlaminar stabilization (ILS) received a Category I Current Procedural Terminology (CPT ${ }^{\circledR}$ ) code 22867. The current work relative value units (wRVUs) assigned to the procedure of 13.5 are not reflective of the amount of work involved. During the survey process, CPT ${ }^{\circledR}$ 22867 was erroneously assessed with a percutaneous "sister" code (CPT ${ }^{\circledR} 22869$ ), which is performed with no decompression (but within the same new "family") and primarily by nonsurgeons. However, similar CPT ${ }^{\circledR}$ code descriptors assigned to each of these new codes undermined their procedural differences during the survey process and generated confusion among physician survey responders, the American Medical Association/Specialty Society Relative Value Scale Update Committee (RUC), and ultimately the Centers for Medicare and Medicaid Services (CMS) regarding the value of ILS. The resulting physician payment determination for the ILS procedure has had severe deleterious effects on this procedure being offered to lumbar spinal stenosis (LSS) patients. Our independent societydriven survey presents new data that assess the accuracy of the assigned wRVUs for CPT ${ }^{\circledR} 22867$.

Methods: An independent survey was driven by the International Society for the Advancement of Spine Surgery (ISASS) in November 2018 and sent to 58 US surgeons with experience performing open decompression with ILS (CPT $\left.{ }^{\circledR} 22867\right)$ and without financial conflicts of interest as analogous to RUC survey financial disclosure requests. Respondents were asked to compare $\mathrm{CPT}^{\circledR} 22867$ with a list of 10 other comparator $\mathrm{CPT}^{\circledR}{ }^{\circledR}$ codes reflective of common spine surgeries. The survey presented each comparator CPT ${ }^{\circledR}$ code with its code descriptor and corresponding wRVUs alongside the code descriptor for $\mathrm{CPT}^{\circledR}$ 22867. A patient vignette was also provided that describes a typical clinical scenario for the surveyed procedure. Respondents were then asked to indicate which comparator CPT ${ }^{\circledR}$ code on the reference list is most similar to the survey code descriptor and typical patient/service vignette provided, as well as specify estimated wRVUs for $\mathrm{CPT}^{\circledR} 22867$ relative to their selected comparator $\mathrm{CPT}^{\circledR}{ }^{\circledR}$ code. The surgeons' responses were analyzed to determine comparator $\mathrm{CPT}^{\circledR}$ codes and estimated wRVUs.

Results: Among the 28 surgeons who responded to the survey, both open decompression codes $(57.1 \%)$ and fusion codes $(42.9 \%)$ were chosen as most similar to the typical patient/service for CPT ${ }^{\circledR} 22867$. Furthermore, the laminectomy procedure $\left(\mathrm{CPT}^{\circledR}\right.$ 63047) was chosen as the surveyed surgeons' model response for a reference procedure in terms of similar work intensity and time for $\mathrm{CPT}^{\circledR}$ 22867. After calculating the difference between the selected comparator codes and estimated wRVUs, nearly all respondents had a positive calculated difference, indicating that surgeons selected wRVUs lower than they deemed appropriate as a result of the listed $\mathrm{CPT}^{\circledR}$ codes they were required to use. In the spirit of the Rasch analysis, the regression analysis estimated wRVUs for CPT ${ }^{\circledR} 22867$ that are greater than its assigned wRVUs (13.5) and its most comparable procedure (CPT ${ }^{\circledR}$ 63047; reference wRVUs: 15.37).

Discussion and Conclusions: The survey results indicate that the wRVUs assigned to CPT ${ }^{\circledR 2} 2867$ are significantly undervalued at 13.50 and have directly resulted in the underreimbursement for surgeons performing the ILS procedure. This misvaluation of the code has created a supply-and-demand anomaly in which the rate of ILS procedures has flatlined despite increasing rates of fusion procedures and an increasing older population. This anomaly is a cause of concern for policy makers and the health care community for the future of safeguarding patient welfare and procedural innovation. Therefore, understanding the clinical economic impact and appropriately addressing potential misvalued codes, such as the ILS procedure, are critical to protecting the future of patient care.
\end{abstract}

\section{Testing and Regulatory Affairs}

Keywords: relative value units (RVUs), current procedural terminology $\left(\mathrm{CPT}^{\circledR}\right)$, physician payment, $\mathrm{CPT}^{\circledR} 22867$, interlaminar stabilization (ILS), lumbar spinal stenosis (LSS), decompression 


\section{INTRODUCTION}

Lumbar spinal stenosis (LSS) has grown in importance over the past decade in response to the rising older population ${ }^{1-3}$ and has become the most common surgical indication for people over 65 years of age. ${ }^{1,4}$ In the United States, Deyo et $\mathrm{al}^{5}$ found that from 2002-2007, there were 135.5-137.5 persons 100000 Medicare beneficiaries aged 65 and older who underwent lumbar stenosis surgery. In 2007 alone, hospital costs for LSS operations accounted for almost $\$ 1.65$ billion (2009 dollars). ${ }^{5}$ Notably, in conjunction with the increasing incidence of LSS, the frequency of more-invasive lumbar spinal procedures, such as complex fusions, has substantially increased. ${ }^{5}$ This may be due to the increasing incidence of associated comorbidities that compounds the severity of LSS. ${ }^{6,7}$ One common comorbidity associated with LSS is degenerative spondylolisthesis. $^{7}$ For LSS patients with spondylolisthesis, the addition of instrumented fusion with a posterior laminectomy or laminoforaminotomy is traditionally recommended to avoid postoperative spinal instability. ${ }^{8,9}$

Fusion has been associated with better long-term outcomes than laminectomy alone. ${ }^{10}$ Paradoxically, lumbar spinal fusion accounts for the highest total hospital costs of any surgical procedure in the United States. ${ }^{11}$ In a cross-sectional analysis using national Medicare data from 1992-2003, Weinstein et $\mathrm{al}^{12}$ found a marked increase in rates of fusion and health care costs, with Medicare spending increasing by over $500 \%$ - from $\$ 75$ million to $\$ 482$ million. Furthermore, in a retrospective cohort analysis of Medicare claims from 2002-2007, Deyo et $\mathrm{al}^{5}$ found that the increasing surgical invasiveness associated with simple fusion and complex fusion increased the risk of major complications, 30-day mortality, and resource use over decompression alone. Inconsistent findings ${ }^{12-14}$ on the clinical outcomes of spinal fusion have also been reported.

Developments in novel surgical technology have offered a motion-preserving alternative for LSS patients with or without grade 1 spondylolisthesis. $^{7-9,15}$ One such example is the interlaminar stabilization (ILS) procedure. Unlike a static interspinous stabilization (ISS) procedure that involves a percutaneous approach to implant the device between the spinous processes, ILS involves an open surgical decompression prior to implanting the device between the lamina. ${ }^{9}$ The implant is functionally dynamic and compressible in extension, allowing both flexion and extension of the spine as opposed to fusion. ${ }^{9}$ Furthermore, the flexibility of the interlaminar device allows for it to function as a "third joint" by providing more physiological load transmission over the rigid fusion instrumentation. ${ }^{16,17}$ In contrast, ISS devices are designed to function as spacers and extension blockers. ${ }^{9}$ Peerreviewed published evidence, including a prospective multicenter level 1 clinical study and a randomized controlled level 1 investigational device exemption (IDE) clinical study validates the addition of ILS to be safer, more efficacious, and costeffective than fusion for patients with and without low-grade spondylolisthesis and LSS. ${ }^{18-24}$

On January 1, 2017, a new Category I CPT ${ }^{\circledR}$ code was implemented for the ILS procedure:

- 22867: "Insertion of interlaminar/interspinous process stabilization/distraction device, without fusion, including image guidance when performed, with open decompression, lumbar; single level."

Notably, CPT ${ }^{\circledR}$ code 22867 is 1 of 2 primary codes that replaced a retired temporary code $0171 \mathrm{~T}$. The other primary code was the ISS procedure:

- 22869: "Insertion of interlaminar/interspinous process stabilization/distraction device without open decompression or fusion, including image guidance when performed, lumbar; single level."

In valuing the code, surgical members of the International Society for the Advancement of Spine Surgery (ISASS) noted that the survey process erroneously combined 2 surveys of 2 different procedures: CPT ${ }^{\circledR} 22867$ (open surgical decompression with ILS) and CPT ${ }^{\circledR} 22869$ (no decompression with percutaneous ISS). The differences between these procedures are significant because open laminectomy involves significant blood loss, surgical site pain, extended hospital stay, and weakening paraspinal muscles. ${ }^{25}$ Furthermore, the time and complexity of implanting the ILS device also increases the work intensity of the procedure as compared with $\mathrm{CPT}^{\circledR}$ 22869, given the high technical skill required to access and secure the device in the interlaminar space following open decompression surgery. ${ }^{26}$ In contrast, CPT ${ }^{\circledR} 22869$ is a percutaneous, minimally invasive procedure performed primarily by interventional pain management physicians - not surgeons (Table 1). ${ }^{27,28}$ 
Table 1. 2019 Medicare utilization of CPT ${ }^{\circledR} 22869$ (1 level) and 22870 (2 level). Source: CMS Medicare 5\% 2019 Utilization Database. ${ }^{28}$

\begin{tabular}{|c|c|c|c|c|c|c|}
\hline CPT $^{\circledR}$ Code & Descriptor & $\begin{array}{c}\text { Total } \\
\text { Utilization }\end{array}$ & $\begin{array}{l}\text { Percentage }(\%) \text { of } \\
\text { Pain Doctors }\end{array}$ & $\begin{array}{c}\text { Percentage }(\%) \text { of } \\
\text { Surgeons }\end{array}$ & $\begin{array}{l}\text { Pain Doctor } \\
\text { Utilization }\end{array}$ & $\begin{array}{l}\text { Surgeon } \\
\text { Utilization }\end{array}$ \\
\hline 22869 & $\begin{array}{l}\text { Insertion of interlaminar/interspinous } \\
\text { process stabilization/distraction device, } \\
\text { without open decompression or fusion, } \\
\text { including image guidance when } \\
\text { performed, lumbar; single level }\end{array}$ & 6795 & 97 & 2 & 6571 & 109 \\
\hline 22870 & $\begin{array}{l}\text { Insertion of interlaminar/interspinous } \\
\text { process stabilization/distraction device, } \\
\text { without open decompression or fusion, } \\
\text { including image guidance when } \\
\text { performed, lumbar; second level (List } \\
\text { separately in addition to code for } \\
\text { primary procedure) }\end{array}$ & 2884 & 97 & 2 & 2800 & 55 \\
\hline
\end{tabular}

Surveying these completely distinct codes together resulted in the 2 different procedures becoming conflated. Notably, this conflation was further embellished in the literature, with ILS devices often being erroneously designated as ISS devices or the 2 devices being categorized together as if they are similar. $^{7,9,15}$ In reality, interlaminar devices function differently from ISS devices: Interlaminar devices permit both flexion and extension, whereas ISS devices are only extension blockers. ISASS believes the mistake of confusing $\mathrm{CPT}^{\circledR} 22867$ and $\mathrm{CPT}^{\circledR}$ 22869 has led to later misinterpretation by CMS.

ISASS members also questioned why the insertion of instrumentation and surgical decompression was bundled when no such hybrid code exists among its family of codes. According to Cheng et $\mathrm{al}^{29}$ this rationale for bundling 2 different components in an operation was catalyzed by an erroneous SpineLine article published by the North American Spine Society (NASS) in the July/August 2014 issue. In this article, the NASS stated ${ }^{30}$ :

"Another common misconception is code 63047. Posterior fusion codes that involve disc preparation (22630, 22633) already take into account the decompression work. Using additional decompression codes (63047) is not allowed."

The NASS' erroneous article first effectively propagated a misrepresentation of the decompression (CPT ${ }^{\circledR}$ 63047) element to CMS. They negated and undermined the additional time and risks taken by surgeons in performing the bone work necessary to decompress the neural elements by essentially bundling it with the interbody fusion codes (e.g., $\mathrm{CPT}^{\circledR} 22630$ and 22633). ${ }^{29}$ Their erroneous statement gave the impression that decompression was less work and less time-intensive, though in fact the amount of bone work needed for a complete decompression of a segment is significantly more than that needed to access the interbody space for fusion. ${ }^{29}$ The NASS later recognized the error and clarified its position in the context of the bundling of interbody fusion and decompression in their September/October 2014 issue, stating: ${ }^{31}$

"From the AMA CPT ${ }^{\circledR}$ guidelines, decompression when performed IS separately reportable with the interbody fusion codes, 22630 and 22633. The point made in the original article is that a certain amount of laminectomy is required for the approach in order to perform the interbody fusion. However, when decompression of the nerve roots requires more laminectomy than necessary for the performance of the interbody fusion, this is separately reportable."

The NASS' original publication still led the CMS to essentially bundle the 2 procedures together despite the redaction. This set an alarming precedent of a new interpretation of the decompression element where misadvised opinions and publications laid the foundation for the devaluation of the procedure. $^{29}$

The initial rationale established by the NASS also affected the nomenclature development of $\mathrm{CPT}^{\circledR}$ 22867 , in which the instrumentation was bundled with the decompression procedure. ISASS believes this procedure-bundling decision was erroneous. It created an anomaly within the family of codes because no other hybrid code exists in which the primary surgical procedure is bundled with the instrumentation outside of $\mathrm{CPT}^{\circledR}$ 22867. For example, when instrumentation is required to stabilize the spinal fusion, the instrumentation needed for a posterior fusion $\left(\mathrm{CPT}^{\circledR} 2284-44\right)$ and 
anterior fusion $\left(\mathrm{CPT}^{\circledR}\right.$ 22845-48) are reported separately. Furthermore, $\mathrm{CPT}^{\circledR} 22853$ (insertion of interbody biomechanical devices with integral anterior instrumentation for device anchoring, when performed, to intervertebral disc space in conjunction with interbody arthrodesis, each interspace) is also listed separately from such spinal procedures, similar to the decompression. In a prospective, randomized controlled trial comparing the longterm outcomes of decompression alone, decompression plus fusion, and decompression plus stabilization for degenerative spondylolisthesis, Inose et $\mathrm{al}^{32}$ found that the addition of instrumentation has more potential and theoretical risks than decompression alone due to higher bleeding and longer operative time. Therefore, by bundling the instrumentation with the primary procedure (decompression) in the code descriptor, the code fails to reflect the additional physician effort and risks associated with the ILS procedure.

Due to the confusion generated between the 2 procedures and erroneous code descriptor, CMS dismissed the original valuation proposal by the American Medical Association/Specialty Society Relative Value Scale Update Committee (RUC) for wRVUs of 15.0, which was based on a multisociety survey instrument. CMS argued that the RUC recommendation was an overestimation of the work involved. Instead, CMS favored a crosswalk methodology to $\mathrm{CPT}^{\circledR} 36832$ (revision, open, arteriovenous fistula; without thrombectomy, autogenous or nonautogenous dialysis graft), with wRVUs of 13.5.

ISASS has since met in person with CMS and the Office of Management and Budget separately to argue against CMS' decision and requested the code be reviewed in the winter of 2018. ISASS contended that $\mathrm{CPT}^{\circledR} 36832$ is not a comparable procedure because it is a secondary procedure performed to "maintain patency, excise an aneurysm or bypass a stenosis in an existing AV fistula." 33 In comparison, ILS involves 2 distinct surgical steps: (1) an open decompression and (2) the surgical implantation of an ILS device.

CPT $^{\circledR} 22867$ was further devalued in the PFS 2020 Final Rule with the malpractice RVUs (MP RVUs) reduced by CMS from 3.97 to 3.88 . Members of ISASS asserted that this created a rank-order anomaly between CPT $^{\circledR} 22867$ and CPT $^{\circledR} 63047$ (laminectomy, facetectomy, and foraminotomy [unilateral or bilateral with decompression of spinal cord, cauda equina, and/or nerve roots; eg, spinal or lateral recess stenosis], single vertebral segment; lumbar) in which the MP RVUs of CPT $^{\circledR} 22867$ became lower than the value for $\mathrm{CPT}^{\circledR}$ 63047. Applying the logic behind the building-block method to the ILS procedure, one would assume that the added "block" of the interlaminar device implantation - which represents additional work time and intensity taken by the surgeon-to the open decompression-procedure block (which is the same as $\mathrm{CPT}^{\circledR}{ }^{\circledR}$ 63047) would be reflected by higher MP RVUs for CPT ${ }^{\circledR} 22867 .{ }^{34}$ However, in reality, CMS downgraded the MP RVUs for $\mathrm{CPT}^{\circledR} 22867$ despite the addition of the interlaminar device block. As a consequence, a paradigm has formed between $\mathrm{CPT}^{\circledR} 63047$ and $\mathrm{CPT}^{\circledR} 22867$ wherein surgeons who are performing only the open decompression block are being reimbursed more than surgeons who perform both the open decompression block and the interlaminar device block. In fact, when the surgeon is incapable of implanting the ILS device, the default appropriate coding is 63047, which has RVUs of 15.37.

To address the wRVUs and MP RVUs of CPT ${ }^{\circledR}$ 22867, ISASS submitted evidence to CMS in February 2020 to support its nomination of the code as potentially misvalued. ${ }^{35}$ This evidence included an unpublished retrospective study that collected hospital intraservice time for 117 procedures at 5 different hospital centers. ${ }^{35}$ The data showed a mean surgery and intraservice time of 121 minutes and a median intraservice time of 110 minutes. ${ }^{35}$ In an effort to provide CMS with new compelling data, an independent society-driven survey was conducted to determine comparator $\mathrm{CPT}^{\circledR}$ codes and estimated wRVUs. The goal of the survey was to assess the accuracy of the assigned wRVUs for $\mathrm{CPT}^{\circledR} 22867$.

\section{METHODS}

The survey was driven by ISASS in November 2018 to obtain estimates of the time and complexity of $\mathrm{CPT}^{\circledR} 22867$ by determining comparator $\mathrm{CPT}^{\circledR}$ codes and estimated wRVUs. The survey gave a list of reference $\mathrm{CPT}^{\circledR}$ codes reflective of common surgeries performed by surgeons within a 90-day global period or represented wRVUs that ranged from below 13.5 to above it. Table 2 provides these listed CPT ${ }^{\circledR}$ codes used for comparison in this study and their descriptor along with the wRVUs assigned to each by CMS in 2018. It was assumed that all of the $\mathrm{CPT}^{\circledR}$ codes, excluding $\mathrm{CPT}^{\circledR}$ 22867, were 
Table 2. CPT ${ }^{\circledR}$ codes representative of 2018 wRVUs. Source: OWCP Medical Fee Schedule-Effective October 15, $2018 .{ }^{42}$

\begin{tabular}{|c|c|c|}
\hline CPT $^{\circledR}$ Code & Descriptor & wRVUs \\
\hline 22102 & $\begin{array}{l}\text { Partial excision of posterior vertebral component (eg, spinous process, lamina, or facet) for intrinsic bony } \\
\text { lesion, single vertebral segment; lumbar }\end{array}$ & 11.08 \\
\hline 63030 & $\begin{array}{l}\text { Laminotomy (hemilaminectomy), with decompression of nerve root(s), including partial facetectomy, } \\
\text { foraminotomy and/or excision of herniated intervertebral disc; } 1 \text { interspace, lumbar }\end{array}$ & 13.18 \\
\hline 63047 & $\begin{array}{l}\text { Laminectomy, facetectomy, and foraminotomy (unilateral or bilateral with decompression of spinal cord, } \\
\text { cauda equina and/or nerve root[s], eg, spinal or lateral recess stenosis), single vertebral segment; lumbar }\end{array}$ & 15.37 \\
\hline 63620 & Stereotactic radiosurgery (particle beam, gamma ray, or linear accelerator); 1 spinal lesion & 15.60 \\
\hline 63005 & $\begin{array}{l}\text { Laminectomy with exploration and/or decompression of spinal cord and/or cauda equina, without } \\
\text { facetectomy, foraminotomy or discectomy (eg, spinal stenosis), } 1 \text { or } 2 \text { vertebral segments; lumbar, except for } \\
\text { spondylolisthesis }\end{array}$ & 16.43 \\
\hline 22630 & $\begin{array}{l}\text { Arthrodesis, posterior interbody technique, including laminectomy and/or discectomy to prepare interspace } \\
\text { (other than for decompression), single interspace; lumbar }\end{array}$ & 22.09 \\
\hline 22612 & $\begin{array}{l}\text { Arthrodesis, posterior or posterolateral technique, single level; lumbar (with lateral transverse technique, when } \\
\text { performed) }\end{array}$ & 23.53 \\
\hline 22532 & $\begin{array}{l}\text { Arthrodesis, lateral extracavitary technique, including minimal discectomy to prepare interspace (other than } \\
\text { for decompression); thoracic }\end{array}$ & 25.99 \\
\hline 22533 & $\begin{array}{l}\text { Arthrodesis, lateral extracavitary technique, including minimal discectomy to prepare interspace (other than } \\
\text { for decompression); lumbar }\end{array}$ & 24.79 \\
\hline 22633 & $\begin{array}{l}\text { Arthrodesis, combined posterior, or posterolateral technique with posterior interbody technique including } \\
\text { laminectomy and/or discectomy sufficient to prepare interspace (other than for decompression), single } \\
\text { interspace and segment; lumbar }\end{array}$ & 27.75 \\
\hline
\end{tabular}

valued accurately, and only CPT $^{\circledR} 22867$ was considered to be a potentially misvalued code.

The survey was posted on SurveyMonkey (http:// www.surveymonkey.com), and an email message with the direct link to the survey was disseminated by a representative of the ISASS Coding and Reimbursement Task Force to 58 US surgeons to request their participation. The survey was completed by 28 surgeons who performed ILS and had no financial conflicts of interest (i.e., direct financial interest, $5 \%$ or more financial ownership interest in an organization, ownership of stock options in Paradigm Spine, LLC, which is analogous to RUC survey financial disclosure requests).

The survey presented each comparator $\mathrm{CPT}^{\circledR}$ code with its code descriptor and corresponding wRVUs alongside the code descriptor for $\mathrm{CPT}^{\circledR}$ 22867. A patient vignette (See Appendix) was also given that described a typical clinical scenario for the surveyed procedure. In this vignette, the patient described was 66 years old with a 6-month history of progressive leg pain/claudication with some back pain (visual analog scale [VAS] Back $>50 / 100$, Oswestry Disability Index [ODI] $>40 \%$ ) unresponsive to conservative treatments. MRI demonstrated moderate to severe spinal stenosis at a single level. Flexion/extension radiographs demonstrated none to mild instability $(<3 \mathrm{~mm})$ and up to grade 1

*Paradigm Spine, LLC (acquired by RTI Surgical in 2019; now Surgalign Holdings, Inc) is the original manufacturer of the coflex ${ }^{\circledR}$ device used for the ILS procedure. spondylolisthesis. It is important to note the wRVUs of the surveyed procedure were not provided as part of the survey instrument. Respondents were then asked to choose which of the comparator $\mathrm{CPT}^{\circledR}$ codes on the reference list was most similar to the survey code descriptor and typical patient/service vignette given.

Using the vignette and the $\mathrm{CPT}^{\circledR} 22867$ code descriptor, the survey then asked respondents, on the basis of personal experience, to estimate wRVUs for the surveyed code, which included preoperative, intraoperative, and postoperative service time and work intensity and work intensity relative to the selected CPT ${ }^{\circledR}$ comparator code. Preoperative service time encompassed all physician services provided prior to the operation, including hospital admission work-up, preoperation evaluation, and other preoperative work such as dressing, scrubbing, waiting, and positioning the patient for surgery. Intraoperative service time included all "skin-to-skin" work that is a necessary part of the procedure. Postoperative service time included physician services provided after the procedure and may have also included postoperative care on the day of procedure, patient stabilization in the recovery room, patient visits on the day of the operative procedure, and office visits within the assigned global period of 90 days.

\section{RESULTS}

A total of 28 surgeons met the required criteria and completed the survey. The specialties of the 
Table 3. Specialties of survey participants.

\begin{tabular}{lc}
\hline Specialty & No. (\%) \\
\hline Neurosurgery & $15(54)$ \\
Orthopedics & $13(46)$ \\
\hline
\end{tabular}

physicians are summarized in Table 3. Approximately 54\% represented neurosurgery and $46 \%$ were from orthopedics. They represented urban practices $(81 \%)$ and suburban practices $(19 \%)$ and 4 primary types of practice: solo practice $(22 \%)$; single specialty group (22\%); multispecialty group $(30 \%)$; and medical school faculty practice plan $(26 \%)$. These demographic estimates excluded 1 physician who did not provide this information. For the typical patient vignette, $98 \%$ of respondents agreed the typical patient/service description was accurate.

In Figure 1, the survey results are summarized with each selected comparator $\mathrm{CPT}^{\circledR}$ code listed with its reference wRVUs. The percentage (\%) scores indicate the proportion of the total respondents who selected a procedure to be most similar to $\mathrm{CPT}^{\circledR}$ code 22867 in terms of time and work intensity. The wRVUs for $\mathrm{CPT}^{\circledR}$ code 22867 are also shown for comparison purposes.

Of the listed codes given, the results indicate that both decompression codes (57.1\%) and fusion codes $(42.9 \%)$ were chosen as most similar to the typical patient/service $\mathrm{CPT}^{\circledR}$ 22867. Furthermore, the laminectomy procedure $\left(\mathrm{CPT}^{\circledR}{ }^{\circledR}\right.$ 63047; reference wRVUs: 15.37) was chosen as the most comparable procedure in terms of similar work intensity and time for $\mathrm{CPT}^{\circledR} 22867$.
In Figure 2, the survey responses for estimated wRVUs, which considered preoperative, intraoperative, and postoperative work service time and intensity, were shown. The mean and median estimated wRVUs were 20.6 and 20.0, respectively.

Table 4 shows the differences between each selected comparator $\mathrm{CPT}^{\circledR}$ codes wRVUs and estimated wRVUs. Positive calculated differences indicate $\mathrm{CPT}^{\circledR} 22867$ should be valued higher than the selected $\mathrm{CPT}^{\circledR}$ comparator; negative calculated differences indicate the procedure should be valued lower. As shown in Figure 3, nearly all respondents had a positive calculated difference. Furthermore, among respondents who listed the most comparable procedure, all valued that the wRVUs should be higher based on their estimates (Table 4). This indicates that surgeons selected comparator codes that had lower wRVUs than they would have preferred.

In the spirit of the Rasch analysis, the comparator $\mathrm{CPT}^{\circledR}$ code wRVUs and calculated differences from Table 4 were analyzed by multiple linear regression that adjusts for 5 relative-difficulty (complexity) variables captured during the survey (mental effort, technical effort, physical effort, risk, and overall intensity). In other words, the wRVUs for $\mathrm{CPT}^{\circledR} 22867$ were predicted by using the relative difficulty of the surveyed procedure to the most comparable procedure. The regression analysis of comparator code wRVUs (dependent variable) on the calculated differences (independent variable) estimated an intercept of 20.95. Figure 4 shows the

Frequency of Comparator Codes of Estimated wRVUs of Surveyed Procedure

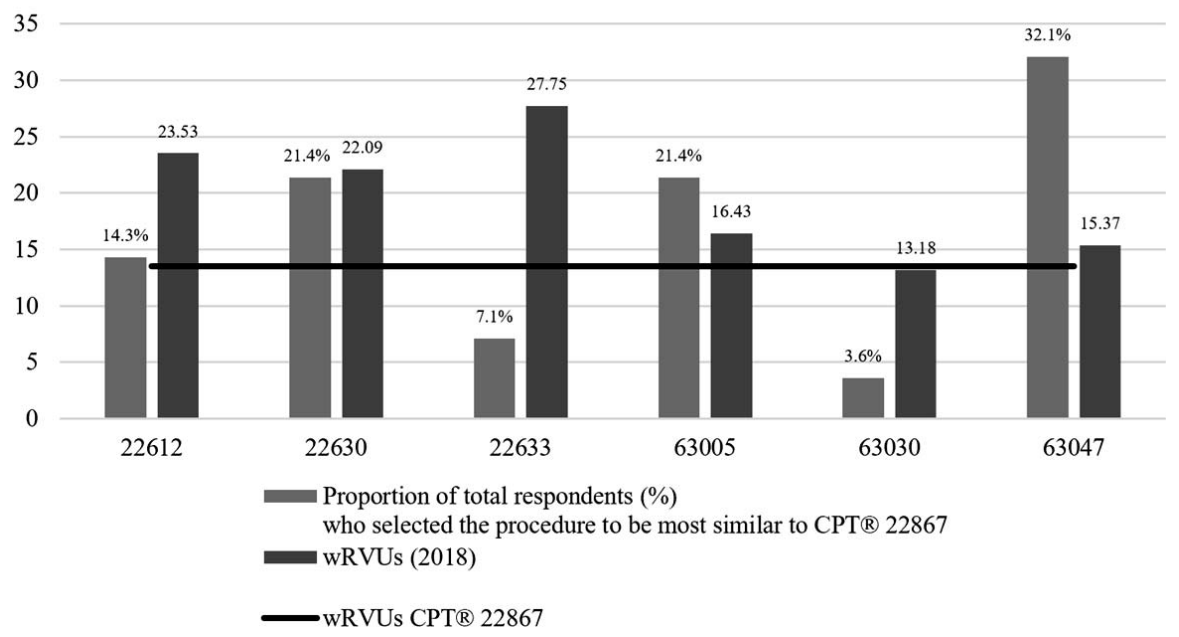

Figure 1. Results of survey of estimated wRVUs for CPT ${ }^{\circledR} 22867$. 
Table 4. Difference between respondents' estimated wRVUs for CPT(R) 22867 and selected comparator $\mathrm{CPT}^{\circledR}$ code wRVUs.

\begin{tabular}{|c|c|c|c|}
\hline $\begin{array}{l}\text { Surgeon } \\
\text { Respondent }\end{array}$ & $\begin{array}{l}\text { wRVUs } \\
\text { Estimates }\end{array}$ & $\begin{array}{l}\text { Selected Comparator } \\
\text { CPT }{ }^{\circledR} \text { Code wRVUs }\end{array}$ & $\begin{array}{l}\text { Calculated } \\
\text { Difference }\end{array}$ \\
\hline 1 & 25.00 & 22.09 & 2.91 \\
\hline 2 & 20.00 & 22.09 & -2.09 \\
\hline 3 & 20.65 & 22.09 & -1.44 \\
\hline 4 & 24.00 & 23.53 & 0.47 \\
\hline 5 & 27.89 & 15.37 & 12.52 \\
\hline 6 & 19.00 & 15.37 & 3.63 \\
\hline 7 & 19.25 & 16.43 & 2.82 \\
\hline 8 & 20.50 & 16.43 & 4.07 \\
\hline 9 & 23.53 & 23.53 & 0.00 \\
\hline 10 & 18.50 & 16.43 & 2.07 \\
\hline 11 & 18.50 & 15.37 & 3.13 \\
\hline 12 & 20.00 & 22.09 & -2.09 \\
\hline 13 & 25.00 & 23.53 & 1.47 \\
\hline 14 & 17.00 & 16.43 & 0.57 \\
\hline 15 & 18.50 & 22.09 & -3.59 \\
\hline 16 & 18.20 & 15.37 & 2.83 \\
\hline 17 & 20.50 & 15.37 & 5.13 \\
\hline 18 & 17.00 & 13.18 & 3.82 \\
\hline 19 & 18.00 & 15.37 & 2.63 \\
\hline 20 & 22.09 & 27.75 & -5.66 \\
\hline 21 & 17.50 & 15.37 & 2.13 \\
\hline 22 & 16.75 & 15.37 & 1.38 \\
\hline 23 & 22.09 & 22.09 & 0.00 \\
\hline 24 & 16.50 & 15.37 & 1.13 \\
\hline 25 & 23.00 & 23.53 & -0.53 \\
\hline 26 & 15.37 & 15.37 & 0.00 \\
\hline 27 & 23.85 & 22.09 & 1.76 \\
\hline 28 & 28.60 & 15.37 & 13.23 \\
\hline
\end{tabular}

results of this analysis. The estimated wRVUs total for $\mathrm{CPT}^{\circledR} 22867$ is 20.95 .

Overall, the survey results indicate that $\mathrm{CPT}^{\circledR}$ 22867 is not only undervalued but is estimated to be closer to approximately $20.0 \mathrm{wRVUs}$, a much higher work value than its most comparable procedure.

\section{DISCUSSION}

According to the 2019 US Census, ${ }^{36}$ the size of the 65-and-older population has rapidly expanded over the past decade, driven by the aging of baby boomers born between 1946 and 1964. Furthermore, due to advancements in medicine, the human life span has dramatically increased. ${ }^{37}$ In the United States alone, it is projected ${ }^{38}$ that by 2030 , more than $20 \%$ of the population will be older than 65 years of age. This represents a significant demographic trend for both the health care community and policy makers in regards to the opportunities and challenges this increasing older population creates. Furthermore, as the incidence of LSS has grown, the frequency of more-complex lumbar spinal procedures has risen, indicating that there is a growing demand by patients for this type of health care. $^{5}$

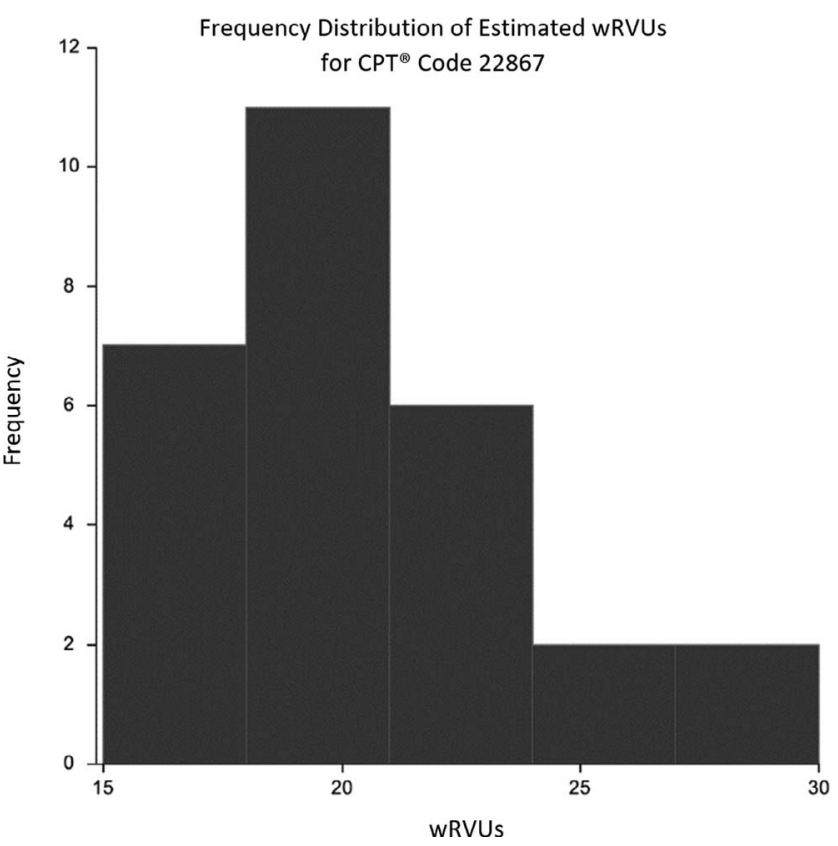

Figure 2. The frequency distribution of estimated wRVUs for CPT ${ }^{\circledR}$ code 22867.

As a surgery that has both an IDE and premarket approval, the ILS procedure presents an alternative solution for select LSS patients to access novel surgical technology. This procedure is supported by a strong evidence base including a US IDE trial (N $=322$ ) that showed equivalent or improved patient outcomes compared with open decompression plus fusion, and a second level 1 clinical trial $(\mathrm{N}=230)$ that proved the superiority of the addition of ILS over decompression alone. ${ }^{18,19}$ Furthermore, Guyer et $\mathrm{al}^{8}$ conducted a thorough review of the clinical data supporting the ILS device, the technical aspects of insertion, and the specific indications that form the inclusion criteria for ILS; the same authors did not support the ISS procedure, which is currently performed by nonsurgeons. ${ }^{8}$ Peer-reviewed published evidence has also demonstrated the relative cost-effectiveness of the outpatient ILS procedure over inpatient fusion. Cost modeling has suggested that ILS procedures performed on appropriately selected patients may lead to an annual savings of $\$ 137740000$ or $\$ 13740$ per patient, compared with traditional fusion. ${ }^{20 \dagger}$

However, despite a strong evidence base, the support of all 3 spine specialty societies (ISASS,

\footnotetext{
†The average costs to create a cost model are based on Medicare 2019 inpatient and outpatient rates for ILS and lumbar spinal fusion procedures.
} 


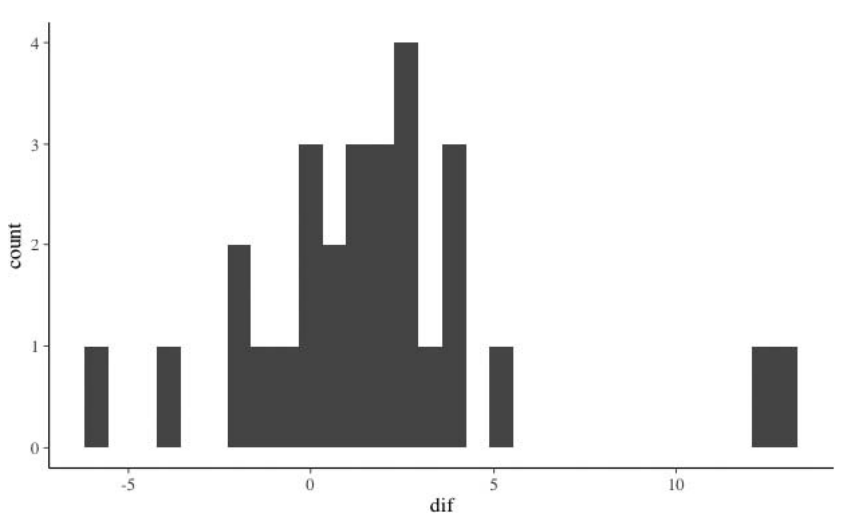

Figure 3. The frequency distribution of the calculated difference between the selected comparator CPT ${ }^{\circledR}$ code and estimated wRVUs.

NASS, American Association of Neurological Surgeons), and the ever-increasing patient demand, the ILS procedure has flatlined. Since its valuation in 2017, the annual number of ILS procedures performed has decreased, whereas the rate of fusion procedures for patients indicated for ILS has concurrently increased (Figure 5). This is despite evidence of inferior patient outcomes, higher complication rates, and higher costs. This supplyand-demand mismatch motivated us to study whether the progressive devaluation of the wRVUs of CPT ${ }^{\circledR} 22867$ had driven this anomaly.

Using the crosswalk methodology of $\mathrm{CPT}^{\circledR}$ 36832, the current wRVUs value for CPT ${ }^{\circledR} 22867$ is 13.5. The results of this study indicate wRVUs that are higher than its most comparable procedure (CPT ${ }^{\circledR}$ 63047) of approximately 20.0. These survey results are supportive of earlier physician time-andeffort surveys as well as retrospective intraservice time and wRVUs surveys that were submitted to CMS that strongly indicated that the complexity and intensity of $\mathrm{CPT}^{\circledR} 22867$ is higher than what is

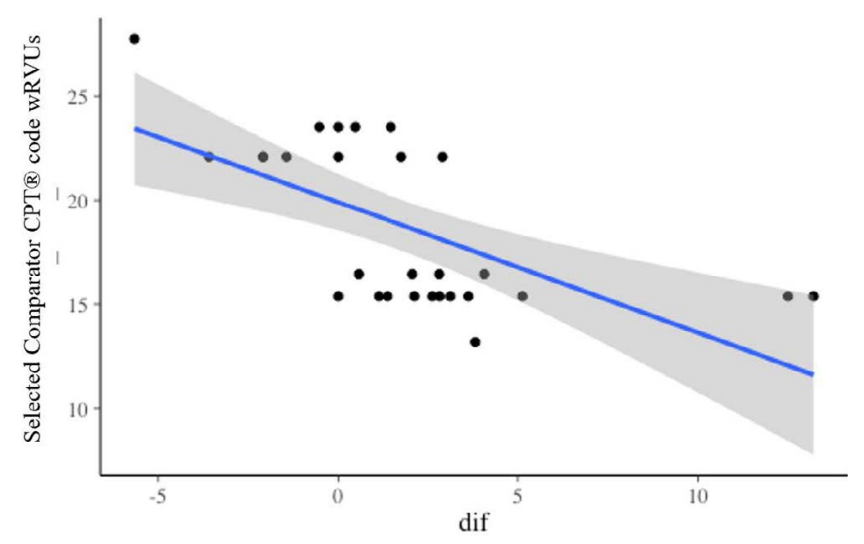

Figure 4. Results of regression analysis of estimated wRVUs of CPT® 22867.

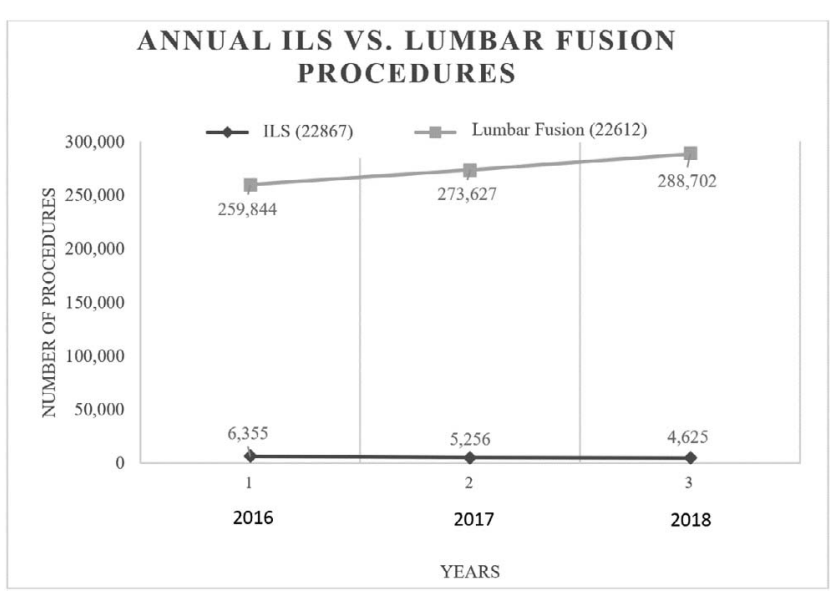

Figure 5. Comparison of 2016-2018 data between frequency of lumbar fusions and interlaminar stabilization (ILS) procedure.

assigned. ${ }^{35}$ The drastic differences between the results of this study and the current wRVUs of $\mathrm{CPT}^{\circledR} 22867$ raise significant questions regarding the validity of the CMS' crosswalk methodology to value $\mathrm{CPT}^{\circledR} 22867$.

There are numerous negative implications attached to misvalued codes, including reduced patient access to emerging technologies and hindering innovation. ${ }^{27,39,40}$ In the case of the ILS procedure, this is particularly apparent as shown in the existing supply-and-demand anomaly. First, the ILS procedure requires specialized training for surgeons to perform the interlaminar device implantation following open surgical decompression. Since the onset of ILS, 2000 surgeons have been trained, of whom more than 1600 have adopted the procedure (Marc Viscogliosi [former CEO of Paradigm and current consultant to Surgalign], written communication, December, 15, 2020). In addition, the cost of the implant is not insignificant. At the current rate of reimbursement, surgeons are being compensated less for performing more-complex work. More surgeons would perform the ILS procedure if surgeons were not economically disadvantaged and actively disincentivized by the current misvaluation of the code procedurally. As a consequence, this has resulted in a serious impediment to physicians'-and, more important, patients' - access to the procedure. ISASS maintains support for ILS procedurally within its policy. ${ }^{8}$ It has also subsequently increased the number of lumbar fusion procedures performed on these select patients, which notably have higher wRVUs (23.53) and higher total costs for payers and patients. 
The anomaly of $\mathrm{CPT}^{\circledR} 22867$ and its current flatline trajectory is a cause for concern for the future of patient access to emerging technologies offering substantial clinical improvement over current standards of care and existing legacy technologies. As the older population increases, innovation is needed to provide high-quality care at a reduced cost. This has been evidenced through the recent introduction of CMS' proposed Medicare Coverage of Innovative Technology (CMS-3372P). ${ }^{41}$ Innovative technology have proven to be an alternative cost-effective solution through the reduction in operation and recovery times and decrease in blood loss. ${ }^{20,22,24}$ Therefore, understanding the clinical economic impact and appropriately addressing potential misvalued codes, such as the ILS procedure, is critical to protecting the future of patient care.

\section{CONCLUSIONS}

We established that the wRVUs value assigned to $\mathrm{CPT}^{\circledR} 22867$ is (1) significantly higher than what is currently assigned by CMS with estimated wRVUs of approximately 20.0 and (2) greater than that of its most comparable procedure (CPT ${ }^{\circledR}$ 63047). These recent data provide new compelling evidence to support the nomination of $\mathrm{CPT}^{\circledR} 22867$ as a misvalued code.

\section{REFERENCES}

1. Sá P, Marques P, Alpoim B, et al. Lumbar stenosis: clinical case. Rev Bras Ortop. 2014;49(4):405-408.

2. Otani K, Kikuchi S, Yabuki S, et al. Lumbar spinal stenosis has a negative impact on quality of life compared with other comorbidities: an epidemiological cross-sectional study of 1862 community-dwelling individuals. Sci World J. 2013(5); 590652.

3. Kalichman L, Cole R, Kim DH, et al. Spinal stenosis prevalence and association with symptoms: the Framingham Study. Spine J. 2009;9(7):545-550.

4. Kuittinen P, Sipola P, Leinonen V, et al. Preoperative MRI findings predict two-year postoperative clinical outcome in lumbar spinal stenosis. PLoS One. 2014;9(9):e106404.

5. Deyo RA, Mirza SK, Martin BI, et al. Trends, major medical complications, and charges associated with surgery for lumbar spinal stenosis in older adults. JAMA. 2010;303(13):1259-1265.

6. Battié MC, Jones CA, Schopflocher DP, Hu RW. Healthrelated quality of life and comorbidities associated with lumbar spinal stenosis. Spine J. 2012;12(3):189-195.

7. Pintauro M, Duffy A, Vahedi P, Rymarczuk G, Heller J. Interspinous implants: are the new implants better than the last generation? A review. Curr Rev Musculoskelet Med. 2017;10(2):189-198.
8. Guyer R, Musacchio M, Cammisa FP Jr, Lorio MP. ISASS recommendations/coverage criteria for decompression with interlaminar stabilization - coverage indications, limitations, and/or medical necessity. Int J Spine Surg. 2016;10(41):120. doi:10.14444/3041

9. Gala RJ, Russo GS, Whang PG. Interspinous implants to treat spinal stenosis. Curr Rev Musculoskelet Med. 2017;10(2):182-188.

10. Ghogawala Z, Dziura J, Butler WE, et al. Laminectomy plus fusion versus laminectomy alone for lumbar spondylolisthesis. $N$ Engl J Med. 2016;374(15):1424-1434.

11. Weiss AJ, Elixhausera A, Andrews RM. Characteristics of operating room procedures in U hospitals, 2011. HCUP statistical brief No. 170. 2014. URL: https://www.hcup-us.ahrq. gov/reports/statbriefs/sb170-Operating-Room-ProceduresUnited-States-2011.jsp. Accessed December 5, 2020.

12. Weinstein JN, Lurie JD, Olson PR, Bronner KK, Fisher ES. United States trends and regional variations in lumbar spine surgery: 1992-2003. Spine (Phila Pa 1976). 2006;31(23):2707-2714.

13. Deyo RA. Treatment of lumbar spinal stenosis: a balancing act. Spine J. 2010;10(7):625-627.

14. Sengupta DK, Herkowitz HN. Degenerative spondylolisthesis: review of current trends and controversies. Spine (Phila Pa 1976). 2005; 30(suppl 6):S71-S81.

15. Gazzeri R, Galarza M, Alfieri A. Controversies about interspinous process devices in the treatment of degenerative lumbar spine diseases: past, present, and future. Biomed Res Int. 2014;975052:1-15. doi10.1155/2014/975052

16. Cajigas I, Varon A, Levenea HB. Interlaminar stabilization and decompression for the treatment of bilateral juxtafacet cysts: case report and literature review. Int J Surg Case Rep. 2019;57:155-159.doi:10.1016/j.ijscr.2019.03.047

17. Nomura H. A novel strategy of non-fusion instrumentation with coflex interlaminar stabilization after decompression for lumbar spinal stenosis. J Spine Surg. 2016;2(2):149153.

18. Rauschmann M, Adelt D, Franke J, et al. Prospective, randomized trial comparing lumbar decompression with or without interlaminar stabilization with 24-month follow-up; proceedings of the 16th Annual Meeting of the International Society for the Advancement of Spine Surgery; 2016 April 6-9, 2016; Las Vegas, NV. Abstract No. 632.

19. Musacchio MJ, Lauryssen C, Davis RJ, et al. Evaluation of decompression and interlaminar stabilization compared with decompression and fusion for the treatment of lumbar spinal stenosis: 5-year follow-up of a prospective, randomized, controlled trial. Int J Spine Surg. 2016;10(6):1-10. doi:10. $14444 / 3006$

20. Schmier JK, Halevi M, Maislin G, Ong K. Comparative cost effectiveness of $\mathrm{Coflex}^{\circledR}$ interlaminar stabilization versus instrumented posterolateral lumbar fusion for the treatment of lumbar spinal stenosis and spondylolisthesis. Clinicoecon Outcomes Res. 2014;6:125-131. doi:10.2147 CEOR.S59194

21. Davis RJ, Errico RJ, Bae H, Auerbach JD. Decompression and Coflex interlaminar stabilization compared with decompression and instrumented spinal fusion for spinal stenosis and low-grade degenerative spondylolisthesis: two-year results from the prospective, randomized, multicenter, Food and Drug Administration investigational device exemption trial. Spine (Phila Pa 1976). 2013;38(18):1529-1539. 
22. Bae H, Lauryssen C, Maislin G, Leary S, Musacchio MJ Jr. Therapeutic sustainability and durability of coflex interlaminar stabilization after decompression for lumbar spinal stenosis: a four year assessment. Int J Spine Surg. 2015;9:1-8. doi: $10.14444 / 2015$

23. Kumar N, Shah SM, Ng YH, Pannierselvam VK, DasDe $\mathrm{S}$, Shen L. Role of Coflex as an adjunct to decompression for symptomatic lumbar spinal stenosis. Asian Spine $J$. 2014;8(2):161-169.

24. Zhang J, Jing X, Cui P, He X, Hao D, Li S. Effectiveness of dynamic fixation Coflex treatment for degenerative lumbar spinal stenosis. Exp Ther Med. 2018;15(1):667-672.

25. Williams MG, Wafai AM, Podmore MD. Functional outcomes of laminectomy and laminotomy for the surgical management lumbar spine stenosis. J Spine Surg. 2017;3(4):580-586.

26. Komp M, Ruetten S. Chapter 18: Full-endoscopic bilateral decompression of central lumbar spinal stenosis with a unilateral interlaminar approach. In: Kim J, Lee JH, Ahn Y, eds. Endoscopic Procedures on the Spine. Singapore: Springer; 2017:243-252.

27. Manchikanti L, Cordner H, Soin A, Diwan S, Sanapati M. Re: CMS-1736: Medicare Program: Changes to hospital outpatient prospective payment and ambulatory surgical center payment systems and quality reporting programs; addition of new categories for hospital outpatient department prior authorization process; clinical laboratory fee schedule: potential revisions to the laboratory date of service policy; proposed overall hospital quality star rating methodology for public release in CY 2021 and subsequent years; and physician-owned hospitals. 2020. https://asipp.org/wp-content/uploads/2020/10/ Comment-Letter-Re-ASC-and-HOPD-2021-PaymentSchedule.pdf. Accessed January 11, 2021.

28. Center for Medicare and Medicaid Services. CMS Medicare 5\% 2019 Utilization Database. 2019. https://www. cms.gov/Research-Statistics-Data-and-Systems/StatisticsTrends-and-Reports/Medicare-Provider-Charge-Data/ Physician-and-Other-Supplier. Accessed: November 18, 2020.

29. Cheng J, Tumialán LM, Ratliff JK. Commentary: the anatomy of disvalued codes: the 63047 and the 22633 . Neurosurgery. 2019;84(2):E122-E126.

30. Saiz P. Lumbar laminectomy code review. SpineLine. July 2014;29-31.

31. Horn S. Lumbar laminectomy code review: clarification. SpineLine. October 2014;44.

32. Inose $\mathrm{H}$, Kato $\mathrm{T}$, Yuasa $\mathrm{M}$, et al. Comparison of decompression, decompression plus fusion, and decompression plus stabilization for degenerative spondylolisthesis a prospective, randomized study. Clin Spine Surg. 2018;31(7):E347-E352.

33. Koksoy C. Brachiobasilic versus brachiocephalic arteriovenous fistula: a randomized prospective study. J Vasc Surg. 2009;49(1):271.

34. Wynn BO, Burgette LF, Mulcahy AW, et al. Development of a Model for the Validation of Work Relative Value Units for the Medicare Physician Fee Schedule. Santa Monica, CA: RAND Corporation; 2015. Report No. RR-662-CMS. https:// www.rand.org/pubs/research_reports/RR662.html. Accessed January 11, 2021.

35. Lorio M. Re: Nomination of CPT ${ }^{\circledR} 22867$ as a misvalued code. 2020. https://www.isass.org/wp-content/uploads/2020/02/ Attachment-G-ISASS-Nomination-of-CPT-22867-as-
Potentially-Misvalued-in-the-Medicare-Physician-FeeSchedule.pdf. January 11, 2021.

36. US Census Bureau. 65 and older population grows rapidly as baby boomers age. 2020. https://www.census.gov/ newsroom/press-releases/2020/65-older-population-grows. html\#: :text=U.S. \% 20Census \%20Bureau \%20Releases \% 202019,born \%20between \%201946\%20and\%201964. January $11,2021$.

37. Wong AYL, Karppinen J, Samartzis D. Low back pain in older adults: risk factors, management options and future directions. Scoliosis Spinal Disord. 2017;12:14.

38. Ortman JM, Velkoff VA, Hogan H. An aging nation: the older population in the United States-population estimates and projections, May 2014. https://www.census.gov/library/ publications/2014/demo/p25-1140.html\#: :text $=\mathrm{In} \% 202050 \%$ $2 \mathrm{C} \% 20$ the $\% 20$ population $\% 20$ aged,over $\% 20$ the $\% 20$ age $\%$ 20of\%2085. Accessed January 17, 2021.

39. Lorio M, Martinson M, Ferrara L. Paired comparison survey analyses utilizing Rasch methodology of the relative difficulty and estimated work relative value units of CPT ${ }^{\circledR}$ code 27279. Int J Spine Surg. 2016;10(40):1-13.

40. American Association of Hip and Knee Surgeons. AAHKS leadership addressing potentially misvalued codes. 2018. http://www.aahks.org/aahks-leadership-addressingpotentially-misvalued-codes/. Accessed January 11, 2021.

41. Center for Medicare and Medicaid Services. Proposed Medicare coverage of innovative technology (CMS-3372-P). 2020. https://www.cms.gov/newsroom/fact-sheets/proposedmedicare-coverage-innovative-technology-cms-3372-p. Accessed January 11, 2021.

42. OWCP medical fee schedule - effective October 15, 2018 https://www.dol.gov/sites/dolgov/files/owcp/regs/feeschedule/ fee/feeOct 1518/Effective_October_15_2018_CPT_HCPCS_ ADA_owcp_CODES_with_RVU_and_Conversion_Factors. pdf. Accessed January 11, 2021.

Disclosure and COI: The authors received no funding for this study. D.L.: None; M.T.: Consultant for ISASS; S.R.G.: Consultant for SpineBioPharma, Inc., Centinel Spine, LLC, Kuros Biosciences AG, Paradigm Spine, LLC/RTI Surgical Holdings, Inc, Simplify Medical, Inc., icotec AG, Intrinsic Therapeutics, Inc., Medacta USA, Inc.; M.P.L.: SAB for VIVEX ${ }^{\circledR}$ Biologics' VIA DISC.

Corresponding Author: Morgan P. Lorio, MD, FACS, Advanced Orthopedics, 499 East Central Parkway, Altamonte Springs, FL 32701. Phone: (407) 960-1717; Email: mloriomd@gmail. com.

Published 26 February 2021

This manuscript is generously published free of charge by ISASS, the International Society for the Advancement of Spine Surgery. Copyright (C) 2021 ISASS. To see more or order reprints or permissions, see http://ijssurgery.com. 


\section{APPENDIX. PHYSICIAN WORK SURVEY}

\section{Survey CPT® Code: 22867}

Global Period: 090

$\mathrm{CPT}^{\circledR}$ Code Descriptor: Insertion of interlaminar/interspinous process stabilization/distraction device, without fusion, including image guidance when performed, with open decompression, lumbar; single level

Typical Patient/Service: A 66-year-old individual presents with a 6-month history of consistent and progressive leg pain/claudication with some back pain (VAS Back > 50/100, ODI > 40/100) unresponsive to conservative treatments including physical therapy, oral medications, and an epidural steroid injection. MRI demonstrates severe spinal stenosis at the L4-L5 level. Flexion-extension radiographs show none to mild instability $(<3$ $\mathrm{mm}$ ) and there may or may not be a grade 1 spondylolisthesis. The patient is scheduled for L4L5 open lumbar decompression and implantation of an interlaminar/interspinous process stabilization/ distraction device.

During the procedure, intraoperative imaging is used to identify the correct level and to plan the surgical incision. A midline posterior lumbar incision is made through the skin, subcutaneous tissue, and lumbosacral fascia. Markers are placed, and intraoperative imaging is used to confirm the correct level of surgery.

A complete decompression of the spinal stenosis to remove any obstructing soft or bony tissue is performed (central, subarticular, and foraminal). If necessary, up to a bilateral $50 \%$ facetectomy may be performed. After the decompression, the lamina and spinous processes of the involved segment are fashioned and prepared to allow for neutral stabilization of the affected vertebral levels. A measuring device is used to determine the size of the interlaminar stabilization device. The implant is selected and the size is verified. Additional shaping and contouring of the lamina and the spinous processes are performed to allow the proper implantation of the interlaminar device. The implant is inserted and fixed into place. Final imaging (anteroposterior and lateral fluoroscopy) is obtained to confirm proper implant position. Copious irrigation is used, and a drain is placed and the wound is closed in layers. 